D.O.I.: $10.3895 / \mathrm{S} 1808-04482006000400011$

\title{
INVESTIMENTO EM RESPONSABILIDADE SÓCIO-AMBIENTAL DE EMPRESAS DISTRIBUIDORAS DE ENERGIA ELÉTRICA: UMA ANÁLISE POR ENVOLTÓRIA DE DADOS
}

\section{SOCIAL AND ENVIRONMENTAL RESPONSIBILITY INVESTMENTS OF ELETRICAL ENERGY DEALER COMPANIES: A DATA ENVELOPMENT ANALYSIS}

\author{
Naja Brandão Santana ${ }^{1}$; Ana Elisa Périco ${ }^{2}$; Daisy Aparecida do Nascimento Rebelatto ${ }^{3}$ \\ ${ }^{1}$ Univerdade de São Paulo - USP - São Carlos - Brasil naja@prod.eesc.usp.br \\ ${ }^{2}$ Universidade de São Paulo - USP - São Carlos - Brasil anaelisa@prod.eesc.usp.br \\ ${ }^{3}$ Universidade de São Paulo - USP - São Carlos - Brasil daisy@prod.eesc.usp.br
}

\begin{abstract}
Resumo
Este trabalho visou discutir a importância dos investimentos em responsabilidade sócio-ambiental para o desempenho financeiro corporativo de empresas distribuidoras de energia elétrica. Para atingir esse fim foi utilizada a ferramenta Análise por Envoltória de Dados (DEA) para calcular a eficiência de 12 empresas desse setor, nos anos de 2003 e 2004, sendo que um dos principais inputs utilizados, para o cálculo da eficiência, foi o investimento em responsabilidade sócio-ambiental. Os resultados alcançados identificam forte correlação entre faturamento corporativo e investimento em responsabilidade sócioambiental.
\end{abstract}

Palavras-chave: responsabilidade sócio-ambiental; eficiência; análise por envoltória de dados.

\section{Introdução, justificativa e objetivo}

Como forma de responder às exigências trazidas pela globalização, as empresas têm implementado um conjunto de transformações que podem ser percebidas, por exemplo, na eficiência financeira, na diversificação de produtos, no atendimento aos desejos de clientes e, também nas ações de responsabilidade sócio-ambiental que, juntos, compõem uma matriz determinante do diferencial competitivo.

O ambiente empresarial desempenha um papel importante na garantia de preservação do meio ambiente e na definição da qualidade de vida das comunidades. As empresas socialmente responsáveis, além de gerar valor para quem está próximo, conquistam resultados melhores para si próprias (KRAEMER, 2004). 
Dessa forma, a assunção do perfil de empresas socialmente responsáveis, deixou de ser uma opção, passando a ser uma questão de visão estratégica e, na maioria dos casos, de sobrevivência no mercado.

Com base na percepção acerca da importância adquirida das práticas de responsabilidade sócio-ambiental pelas empresas, parece necessário relacionar o desempenho financeiro com os investimentos feitos nestas ações, verificando se um aumento nesses últimos acarreta um impacto positivo no primeiro.

Dessa forma, o objetivo deste trabalho consistiu em propor uma discussão sobre a importância dos investimentos em responsabilidade sócio-ambiental para o desempenho financeiro corporativo, utilizando uma ferramenta que identifique essa relação nas empresas selecionadas, considerando propostas de melhorias. Para alcançar esse objetivo, foi realizado um estudo, envolvendo empresas do setor de energia elétrica. Descarta-se qualquer intenção de extrapolar os resultados encontrados para todas as empresas do setor ou para os demais setores da economia.

Busca-se, com esse trabalho, iniciar o preenchimento de uma lacuna existente, no âmbito da pesquisa empírica, sobre a relação entre o desempenho social e o desempenho financeiro corporativo, o que pode ser considerado como uma das justificativas para a escolha do tema.

Outra justificativa diz respeito à importância que esse tema vem ganhando nos fóruns de debates nacionais e internacionais, ao ponto de chamar a atenção de um órgão maior, como a ISO, para a elaboração da norma ISO 26.000, a qual será apresentada na sua forma completa no ano de 2008, fato que trará diversas implicações para o ambiente dos negócios (CAJAZEIRA e BARBIERI, 2005).

\section{Fundamentação teórica}

Nesta seção serão abordados alguns temas relevantes para o alcance do objetivo deste trabalho, tais como definições e histórico da Responsabilidade Social Corporativa, a importante relação entre Desempenho Social e Desempenho Financeiro e uma relevante e muito recente forma de analisar a eficiência de organizações, a Análise por Envoltória de Dados (DEA)

\subsection{Responsabilidade Social Corporativa (RSC) - Definições e Histórico}

A expressão Responsabilidade Social Corporativa (RSC) vem adquirindo, ao longo dos últimos 50 anos, as mais variadas definições. Segundo Carroll (1999), a década de 50, do séc. XX, pode ser considerada como o ponto inicial das discussões sobre a Responsabilidade Social dos negócios. Bowen (1953) foi o principal responsável pelo início do debate acerca da 
Responsabilidade Social para o ambiente empresarial, com o seguinte questionamento: “Quais responsabilidades devem ser esperadas que os homens de negócios assumam para com a sociedade?" (BOWEM, 1953, p. XI).

Assim, Bowen (1953 apud CARROLL,1999), apresentou uma primeira definição para tais responsabilidades sociais: "[...] obrigações dos homens de negócios em perseguir as políticas, a tomar decisões ou a seguir linhas de ação que fossem desejáveis em termos de objetivos e valores para a sociedade" (BOWEM, 1953, apud CARROLL, 1999, p. 270).

Foi na década de 1960, que a definição de Davis (1960) sobre RSC expandiu-se e assumiu contornos mais claros. Nela, a Responsabilidade Social refere-se às decisões e ações, tomadas pelos homens de negócios, por razões que vão além dos interesses econômicos e técnicos diretos. Nessa mesma linha, McGuire (1963) afirmou que a utilização da Responsabilidade Social supõe que as empresas não possuem apenas obrigações econômicas e legais, mas também responsabilidades para com a sociedade.

Na década de 1970, o termo RSC começou a ser utilizado para a elaboração do conceito de desempenho social corporativo, conceito muito pouco operacional na época. Contudo, seria no final daquela década que surgiria uma das mais importantes contribuições teóricas sobre o termo RSC. Carroll (1979) definiu RSC como o desempenho corporativo em quatro categorias de responsabilidade: responsabilidades econômicas (tidas como fundamentais e sendo a base para todas as outras); responsabilidades legais (definidas como parte integrante do contrato social entre empresa e sociedade); responsabilidades éticas (apesar de não serem necessariamente especificadas em leis e regulamentações, são esperadas pelos membros da sociedade em relação às empresas); responsabilidades discricionárias (aquelas que os negócios têm a liberdade de assumir ou não, tendo natureza voluntária por parte das empresas).

Baseado nessas quatro categorias de RSC, Carroll (1979) define que: “A RSC dos negócios abrange as expectativas econômicas, legais, éticas e discricionárias que a sociedade possui em relação às organizações em determinado período de tempo" (CARROLL, 1979, p.500).

Na década de 1980, uma das mais importantes definições, consideradas novas, foi elaborada por Drucker (1984), na qual surgiu a idéia de que a lucratividade e a responsabilidade não seriam simplesmente compatíveis, mas que os negócios poderiam converter responsabilidades sociais em oportunidades de negócio.

Posteriormente, na década de 1990, temas alternativos continuaram surgindo no campo da RSC, como desempenho social corporativo, Teoria dos Stakeholders, teoria ética dos negócios e cidadania corporativa. (CARROLL, 1999). 
Em 2000, estudos empíricos que tratam da relação entre desempenho social e financeiro corporativos conquistaram espaço ainda maior, já que a criação de indicadores sociais nas décadas anteriores possibilitaram a formação de dados para a realização de pesquisas, ao mesmo tempo em que, o maior desenvolvimento dos testes estatísticos e a evolução conceitual e operacional do termo desempenho social corporativo, favoreceram o aperfeiçoamento dessas pesquisas.

Esse era o cenário internacional quando, no Brasil, segundo Fischer (2003), o conceito de Responsabilidade Social apareceu com muita evidência sob a forma da responsabilidade corporativa, associado às iniciativas empresariais de intervenção social, ou de apoio a projetos, programas e entidades voltados à ação social.

A importância que a RSC adquiriu com a crescente cobertura da mídia acerca da atuação empresarial no meio social, por meio de inúmeros projetos e programas, tem estimulado a retomada desse conceito no Brasil. Contudo, devido à inconsistência teórica do próprio tema RSC, o trabalho realizado pela mídia distorce esse termo, chegando, mesmo, a fragilizá-lo.

Como pode ser visto, é crescente o espaço que a RSC vem conquistando na mídia. Esse tema também se faz presente na organização e na atuação de diversas entidades da sociedade civil, como o IBASE, o Instituto Ethos de Empresas de Responsabilidade Social, a Fundação Instituto de Desenvolvimento Empresarial e Social (FIDES) e o Grupo de Institutos, Fundações e Empresas (GIFE).

No meio empresarial brasileiro, a partir dos resultados de algumas pesquisas, pode-se constatar que muitas empresas vêm aumentando sua atuação social por meio de ações e programas de intervenção, motivadas pela percepção crescente de que o exercício da Responsabilidade Social pode trazer retornos, embora conte com pouca comprovação empírica.

Vale a pena registrar que, em 2001, o Banco Nacional de Desenvolvimento Econômico e Social (BNDES) divulgou um relatório no qual relacionou empresas e Responsabilidade Social, identificando uma possível existência de ganhos de reputação positiva (BRASIL, 2001).

Diante desse contexto desenvolveu-se, no Brasil, um ambiente propício para um melhor aprofundamento do debate empírico referente ao tema RSC uma vez que, desse modo, segundo Fischer (2003, p. 21):

[...] a Responsabilidade Social é tomada como um conceito amplo, no qual a empresa, preservando seus compromissos de negócio, cria métodos, planos e incentivos, para que, interna e externamente, consiga colaborar com as expectativas de equilíbrio e justiça da sociedade, excedendo as funções que estão estabelecidas em lei e os próprios interesses inerentes aos seus negócios (FISCHER, 2003). 


\subsection{Desempenho financeiro corporativo $\mathrm{x}$ desempenho social corporativo}

No atual estágio da abordagem conceitual pode ser viabilizada a relação comparativa entre o desempenho social corporativo e o desempenho financeiro corporativo. Para que se tornasse possível a realização de pesquisas empíricas acerca dessa relação, foi necessária uma melhor elaboração da categoria desempenho social corporativo, bem como a busca de indicadores e de valores que melhor representassem ambos os desempenhos. Essa necessidade fornece subsídios para que a investigação assuma a sua dimensão qualitativa.

$\mathrm{Na}$ elaboração que faz do conceito do desempenho social corporativo, cuja definição encontra-se, ainda, em desenvolvimento, Jones (1980) entende que ele poderia ser compreendido como uma medida do comportamento da empresa em relação aos vários grupos componentes do ambiente do negócio.

Visto por esse prisma, o desempenho social corporativo demonstra um relacionamento entre a RSC e a Teoria dos Stakeholders, especialmente em relação ao aspecto instrumental desta teoria, uma vez que é este aspecto que norteará a investigação na comprovação da natureza da relação entre o desempenho social e o financeiro.

A existência de inúmeras definições para o desempenho social corporativo dificultou bastante a construção de indicadores ou de representações deste desempenho e mesmo a realização de estudos empíricos comparativos entre desempenho social e financeiro. Isso deu origem a diversas críticas e questionamentos, principalmente na inconsistência e na alta variabilidade nos resultados alcançados. A grande variedade de indicadores sociais foi a principal causa das dificuldades, segundo Griffin e Mahon (1997).

O desempenho financeiro corporativo é facilmente definido em termos de maximização da riqueza dos proprietários. Entretanto, pesquisas sobre a relação entre desempenho social e desempenho financeiro corporativo ainda não apresentam informações suficientes acerca das medidas que devem ser utilizadas.

Uma questão desafiadora para a análise da relação entre o desempenho social corporativo e desempenho financeiro corporativo é a falta de um indicador que incorpore, de fato, o conceito de RSC. Vale salientar que, apesar de muitas críticas e fragilidades, esse tipo de estudos empíricos vem evoluindo constantemente.

A maior parte dos estudos realizados sobre a relação entre o desempenho social corporativo e o desempenho financeiro corporativo, identifica relações positivas, negativas ou nulas. Pava e Krausz (1996) formularam duas hipóteses principais para essa relação. A primeira delas foi a hipótese tradicionalista, onde as atividades sociais das empresas seriam consideradas custosas e prejudiciais à empresa, enquanto a segunda hipótese é aquela identificada com o "paradoxo do 
custo social", que diz que existiria uma relação positiva entre desempenho social e financeiro.

$\mathrm{Na}$ fase inicial desse tipo de pesquisa, um grande número de pesquisadores não encontrou qualquer relação significativa entre Responsabilidade Social e desempenho financeiro. Contudo, pode ser visto que para a realização desse tipo de pesquisa, deve ser levada em consideração a necessidade de um espaço de tempo de longo prazo para que os resultados e os efeitos econômicos na empresa, originados de ações responsáveis, possam ser observados. Além de considerar o longo prazo, outros fatores influenciam esse tipo de pesquisa como, por exemplo, o tamanho da empresa e a lucratividade. Isso somente pode ser constatado a partir da pesquisa de Stanwick e Stanwick (1998) quando foi demonstrada a relação positiva significativa com o desempenho social corporativo em diversas equações de regressão.

A relação entre desempenho social corporativo e desempenho financeiro corporativo tem sido alvo de muitas críticas. Segundo Ullmann (1985), isso se dá devido à falta de uma base teórica sólida, à definição inapropriada de termos-chave e às deficiências existentes nos bancos de dados, hoje disponíveis.

Contudo, as críticas aos estudos acerca da relação entre desempenhos social e financeiro das empresas têm que ser levadas em conta porque é a partir delas que as pesquisas tendem a se aperfeiçoar, alcançando resultados melhores e mais convincentes.

\subsection{Análise por Envoltória de Dados}

Os estudos das medidas de eficiência, baseados em técnicas não-paramétricas, tiveram início com Farrel (1957), que propôs um modelo empírico para eficiência relativa, em oposição ao modelo de função de produção teórica. Segundo este autor, é melhor determinar a medida de eficiência de uma firma ou unidade administrativa comparando-a com o melhor nível de eficiência até então observado, do que compará-la com algum ideal inatingível.

O resultado da aplicação da Análise por Envoltória de Dados (DEA) é utilizado para fazer a classificação das empresas como eficientes e ineficientes. Segundo Farrel (1957), o conceito de eficiência produtiva é visto como o sinônimo de eficiência técnica, e ele mesmo propõe uma técnica para a medição de eficiência. Assumindo vários inputs ( $\left.\mathrm{x}_{1} \mathrm{e} \times \mathrm{x} 2\right)$ para um único produto a rendimentos constantes de escala, Farrel adotava a combinação eficiente de inputs x1 e x2, para um dado nível de output como referência, sendo os desvios classificados como ineficiência. Pode ser notado que naquela época o autor já trabalhava com a idéia de melhor combinação entre inputs para gerar o máximo de output, buscando reduzir os recursos a um nível considerado eficiente. 
Passadas cerca de duas décadas, os estudos de Farrel foram redescobertos. Charnes, Cooper e Rhodes em 1978 generalizaram esses estudos o que deu origem a essa nova técnica de construção de fronteiras de produção e indicadores da eficiência produtiva, conhecida como DEA.

A partir daí, a forma mais utilizada para quantificar a eficiência, mediante a razão entre output e input está representada na seguinte equação:

\section{Eficiência $=$ Soutput $/ \sum$ input}

A fronteira de eficiência é construída pelos valores observados de insumos e produtos. A técnica DEA consiste em um método que compara cada firma com a melhor firma. Segundo Casa Nova (2002), a DEA define a curva de eficiência (máxima produtividade), considerando a relação ótima input/output. Assim, são identificadas as unidades que obtiveram a alocação ótima entre insumos e produtos, que são chamadas de eficientes e estão posicionadas na curva de máxima eficiência relativa. A Figura 1 mostra uma curva de eficiência obtida a partir da análise DEA.

Figura 1 - Curva de eficiência

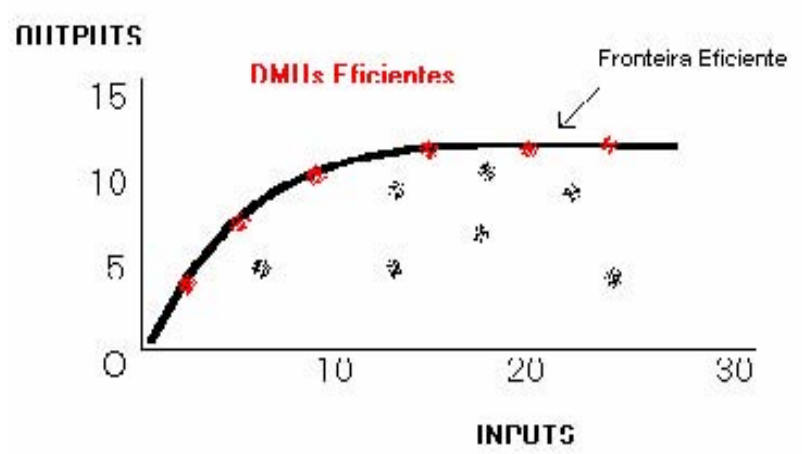

Fonte: Própria

Para Oliveira e Gomes (2003), uma pressuposição fundamental na técnica DEA é que, se uma determinada firma A é capaz de produzir $\mathrm{Y}(\mathrm{A})$ unidades de produtos, utilizando-se X(A) unidades de insumos, outras firmas poderiam também fazer o mesmo, caso elas estejam operando eficientemente. De forma similar, se uma firma B é capaz de produzir Y(B) unidades de produtos, utilizando-se $\mathrm{X}(\mathrm{B})$ de insumos, então outras firmas poderiam ser capazes de realizar o mesmo esquema de produção. Caso as firmas A e B sejam consideradas eficientes, elas poderiam ser combinadas para formar uma firma composta, que utiliza uma combinação de insumos para produzir uma combinação de produtos. 
É importante notar que a técnica DEA conta com a formulação de dois modelos: o modelo CCR e o modelo BCC. Segundo Paiva (2000), esses dois modelos produzem diferentes fronteiras de eficiência, uma vez que eles utilizam diferentes tipos de tecnologia. O primeiro deles supõe o retorno de escala constante e o último supõe o retorno de escala variável.

\section{Método de pesquisa}

Este trabalho teve natureza exploratória, pois buscou avaliar como as ações de responsabilidade sócio-ambiental se relacionam com o desempenho financeiro de empresas, a fim de identificar e, quando possível, quantificar tal relação.

Alguns critérios como a existência de ações de responsabilidade sócio-ambiental nas empresas pesquisadas e a freqüência das mesmas, bem como o acesso aos dados necessários, foram os balizadores da seleção das empresas para a pesquisa. As empresas foram selecionadas a partir de uma amostra intencional e guardam determinado grau de familiaridade, de forma que a comparação entre elas seguisse concordância com as exigências científicas, e possuíam performances distintas, de forma a haver discriminação entre elas. Para o caso deste trabalho, algumas características fizeram com que as empresas que foram selecionadas fossem consideradas similares: pertencer ao setor de energia elétrica; ser empresas de capital aberto; e ter publicado o Balanço Social, seguindo as diretrizes do IBASE.

O número de unidades (empresas) a ser incluída na análise foi suficientemente grande para que fosse possível a discriminação entre elas. O modelo DEA (Data Envelopment Analysis) sugeriu que o número ideal de unidades a ser avaliadas fosse, no mínimo, três vezes a soma dos output e inputs, incluídos na especificação. Portanto, para este caso, o número de empresas a serem analisadas totaliza 12 unidades. A Tabela 1 identifica as variáveis utilizadas neste trabalho.

As variáveis de input utilizadas neste trabalho são: ativo total, mão de obra, investimentos sócio-ambientais. E a variável de output utilizada é o faturamento da empresa. Todas as variáveis estão em valor monetário.

Os dados coletados referem-se aos anos de 2003 e 2004, ou seja, os anos mais recentes da publicação do Balanço Social. Além disso, deve-se considerar que os anos que a pesquisa se refere podem ser caracterizados como o período em que houve disponibilidade completa dos dados necessários. A Tabela 1 apresenta os dados coletados, de inputs e output, para as 12 empresas selecionadas. Os dados aqui apresentados foram coletados a partir das Demonstrações Contábeis e dos Balanços Sociais das respectivas empresas. 
Tabela 1 - Dados de inputs e output das empresas selecionadas (em R $\$$ mil reais)

\begin{tabular}{|l|r|r|r|l|r|r|r|r|}
\hline \multirow{2}{*}{ Empresa } & \multicolumn{3}{r|}{ Ativo Total } & \multicolumn{2}{|c|}{ Mão-de-Obra } & \multicolumn{2}{l|}{ Inv. Sócio-ambiental } & \multicolumn{2}{l|}{ Faturamento } \\
\cline { 2 - 9 } & $\mathbf{2 0 0 3}$ & $\mathbf{2 0 0 4}$ & $\mathbf{2 0 0 3}$ & $\mathbf{2 0 0 4}$ & $\mathbf{2 0 0 3}$ & $\mathbf{2 0 0 4}$ & $\mathbf{2 0 0 3}$ & $\mathbf{2 0 0 4}$ \\
\hline BANDEIRANTE & 2.326 .579 & 2.432 .826 & 116.831 & 120.522 & 718.345 & 758.560 & 1.674 .395 & 2.509 .001 \\
\hline CEB & 1.180 .279 & 1.250 .834 & 116.585 & 122.090 & 373.951 & 469.211 & 694.908 & 775.040 \\
\hline CELESC & 2.988 .001 & 3.117 .850 & 263.835 & 316.246 & 906.126 & 1.759 .095 & 2.139 .020 & 3.919 .315 \\
\hline CELG & 2.692 .528 & 3.019 .972 & 174.579 & 162.609 & 660.057 & 844.637 & 1.157 .740 & 1.493 .224 \\
\hline CELPE & 2.620 .422 & 2.860 .542 & 49.577 & 61.853 & 97.513 & 804.479 & 1.185 .491 & 1.397 .925 \\
\hline CEMIG & 14.852 .086 & 16.813 .614 & 638.460 & 784.511 & 3.925 .787 & 4.584 .685 & 5.239 .039 & 9.748 .018 \\
\hline COELBA & 4.137 .830 & 4.110 .225 & 176.511 & 204.328 & 593.187 & 875.699 & 1.781 .053 & 2.925 .452 \\
\hline COPEL & 6.538 .659 & 6.747 .240 & 538.009 & 380.124 & 1.812 .879 & 2.036 .079 & 2.990 .822 & 5.544 .300 \\
\hline CPFL & 12.050 .000 & 12.618 .000 & 147.302 & 159.836 & 2.535 .119 & 3.288 .155 & 6.057 .069 & 9.549 .000 \\
\hline ELEKTRO & 3.476 .535 & 3.450 .507 & 151.566 & 150.097 & 710.395 & 928.303 & 1.785 .234 & 2.929 .640 \\
\hline LIGHT & 10.405 .115 & 10.456 .442 & 215.409 & 214.634 & 1.737 .951 & 1.868 .323 & 3.780 .084 & 5.846 .345 \\
\hline RGE & 2.258 .436 & 2.271 .361 & 33.773 & 38.157 & 420.968 & 545.057 & 1.169 .121 & 1.356 .449 \\
\hline
\end{tabular}

4. Aplicação da Ferramenta Análise por Envoltória de Dados (DEA)

\subsection{Correlação entre as variáveis}

O conceito de correlação permite que se verifique a relação entre as variáveis propostas. Para este caso específico, é importante que se verifique a existência da correlação entre as variáveis de inputs e output, de forma a avaliar se as primeiras possuem poder associativo sobre a segunda. É importante a associação entre as variáveis de output e inputs, pois, embora esta associação não tenha poder explicativo sugere que as variáveis estão relacionadas. Quanto mais próximo o valor da correlação estiver do número 1 e do número -1, maior o grau de associação.

Com a aplicação da DEA, foi possível identificar o coeficiente de correlação entre as variáveis de inputs e a variável de output. Os índices de correlação entre o Ativo Total e o Faturamento para os anos de 2003 e 2004 foram, respectivamente, 0,96 e 0,95. Para o caso de Mãode-obra e Faturamento, os índices encontrados para os dois períodos subseqüentes foram de 0,55 e 0,70. E, por fim, o índice de correlação existente entre Investimentos em responsabilidade sócioambiental e Faturamento, também nos dois períodos analisados foram de 0,91 e 0,96. Apresenta-se de grande relevância os altos índices de correlação encontrados entre as variáveis de input e output, nos dois anos analisados.

\subsection{Orientação do Modelo adotado}

A ferramenta DEA permite que os resultados sejam analisados sob duas orientações, para o input e para o output. Para fins deste trabalho, foi adotada a orientação output, buscando aumentar o faturamento, mantendo os níveis das variáveis de inputs e verificando a relevância de cada uma dessas variáveis, especialmente a de Investimentos em responsabilidade sócio-ambiental, para o incremento do resultado (output). 


\subsection{Pontuação de Eficiência a partir da DEA}

As unidades consideradas eficientes possuem pontuação de 100. A partir da aplicação da ferramenta DEA foi obtido um score classificatório indicando a eficiência técnica de cada unidade analisada, para os anos de 2003 e 2004, conforme observado na Tabela 2.

Tabela 2 - Scores de eficiência para o período 2003-2004

\begin{tabular}{|c|l|}
\hline Unidade & Pontuação \\
\hline RGE & 100,00 \\
\hline Celpe & 100,00 \\
\hline Bandeirante & $\mathbf{1 0 0 , 0 0}$ \\
\hline CPFL & $\mathbf{1 0 0 , 0 0}$ \\
\hline Celesc & $\mathbf{1 0 0 , 0 0}$ \\
\hline Elektro & $\mathbf{8 3 , 2 1}$ \\
\hline Ceb & 81,81 \\
\hline Coelba & 77,23 \\
\hline Light & 68,63 \\
\hline Copel & 66,28 \\
\hline Celg & 65,35 \\
\hline Cemig & 52,82 \\
\hline
\end{tabular}

\begin{tabular}{|c|l|}
\hline Unidade & Pontuação \\
\hline Bandeirante & $\mathbf{1 0 0 , 0 0}$ \\
\hline Coelba & 100,00 \\
\hline Celesc & $\mathbf{1 0 0 , 0 0}$ \\
\hline CPFL & $\mathbf{1 0 0 , 0 0}$ \\
\hline Light & 99,32 \\
\hline Elektro & 95,38 \\
\hline RGE & 83,45 \\
\hline Copel & 82,27 \\
\hline Cemig & 64,18 \\
\hline Celpe & 59,35 \\
\hline Ceb & 56,95 \\
\hline Celg & 53,32 \\
\hline
\end{tabular}

A Tabela 3 mostra os resultados da análise estatística, para o ano de 2003. O resultado da análise mostrou eficiência média de $82,94 \%$, para o conjunto de empresas em 2003, com 5 empresas eficiente, 4 empresas com indicador de eficiência menor que $75 \%$ e nenhuma empresa com indicador de eficiência menor que $50 \%$.

Tabela 3 - Resultados do modelo DEA para 2003

\begin{tabular}{|c|c|}
\hline Variáveis & Resultados \\
\hline Eficiência Média & 82,94416667 \\
\hline Desvio-Padrão & 17,02438329 \\
\hline Coeficiente de Variação & 0,205251122 \\
\hline Variância & 289,8296265 \\
\hline Mínimo & 52,82 \\
\hline Mediana & 82,51 \\
\hline Máximo & 100 \\
\hline Número de empresas eficientes & 5 \\
\hline Empresas com indicador $<75 \%$ & 4 \\
\hline Empresas com indicador $<50 \%$ & 0 \\
\hline
\end{tabular}

A Tabela 4 mostra os resultados da análise, para o ano de 2004. 
Tabela 4 - Resultados do modelo DEA para 2004

\begin{tabular}{|c|c|}
\hline Variáveis & Resultados \\
\hline Eficiência Média & 82,85166667 \\
\hline Desvio-Padrão & 19,18592753 \\
\hline Coeficiente de Variação & 0,231569603 \\
\hline Variância & 368,0998152 \\
\hline Mínimo & 53,32 \\
\hline Mediana & 89,415 \\
\hline Máximo & 100 \\
\hline Número de empresas eficientes & 4 \\
\hline Empresas com indicador $<75 \%$ & 4 \\
\hline Empresas com indicador $<50 \%$ & 0 \\
\hline
\end{tabular}

O resultado da análise mostrou eficiência média de $82,85 \%$, para o conjunto de empresas em 2003, com 4 empresas eficiente, 4 empresas com indicador de eficiência menor que $75 \%$ e nenhuma empresa com indicador de eficiência menor que $50 \%$.

Neste trabalho será dedicada atenção ao grupo de empresas considerado eficiente, nos dois períodos e, dessa forma, identificar a continuidade de empresas no ranking classificatório e explicar a trajetória das recém classificadas. Dessa forma, foi possível identificar que no ano de 2003 cinco empresas foram consideradas eficientes: RGE, Celpe, Bandeirante, CPFL e Celesc. Para o ano de 2004, foi possível identificar quatro empresas eficientes: Bandeirante, Coelba, Celesc e CPFL.

A partir desses resultados iniciais, é possível identificar empresas consideradas eficientes nos dois períodos, como: Bandeirante, Celesc e CPFL. Portanto, para tais empresas não cabe analises mais aprofundadas, uma vez que elas mantiveram o nível de eficiência.

Seguindo o esquema proposto, segue a aplicação da ferramenta DEA. Tal ferramenta permite identificar, entre as variáveis de inputs das empresas, a margem de contribuição que cada input possuía em relação ao output. Tal procedimento somente foi realizado para as empresas que deixaram de ser eficientes de um período para outro (RGE e Celpe) e para a empresa que passou a ser eficiente de 2003 para 2004 (Coelba).

De forma a facilitar o entendimento, a Figura 2 apresenta o resultado da aplicação da ferramenta DEA para as três empresas (RGE, Celpe e Coelba) analisadas no referido período. A figura apresenta a contribuição de cada input para o alcance de determinado nível de output. 
Figura 2 - Margem de contribuição de input para o output
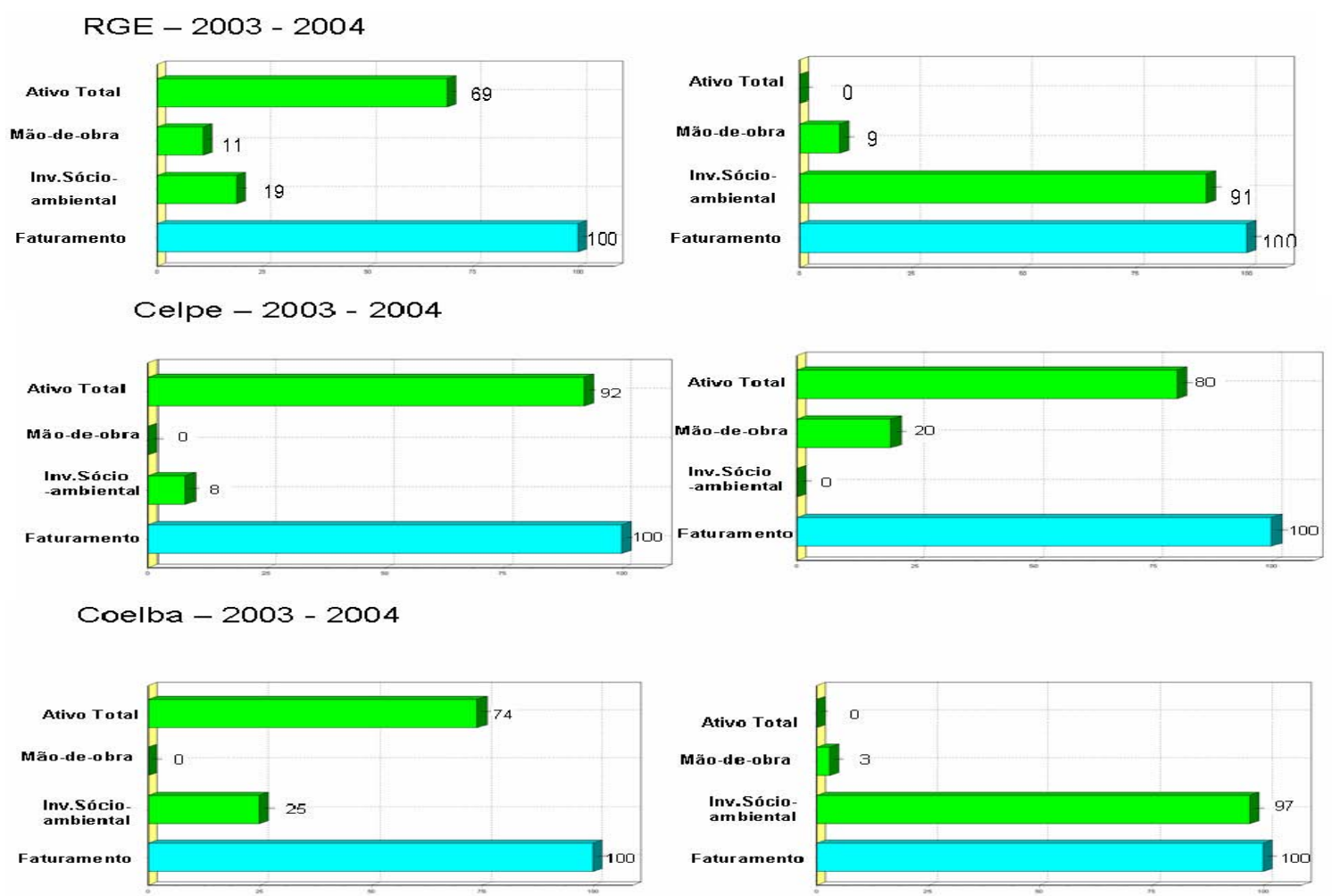

Fonte: Própria

A primeira empresa analisada foi a RGE. Cabe ressaltar que no ano de 2003, o input Ativo Total contribuiu para $69 \%$ do Faturamento (output) da empresa. E os inputs Mão-deobra e Investimentos sócio-ambientais contribuíram, respectivamente, 11\% e 19\% do Faturamento da empresa (output). No ano de 2004, contrariamente o input Ativo Total contribuiu para 0\% do Faturamento da RGE, enquanto os inputs de Mão-de-obra e Investimento Sócio-Ambiental contribuíram para, respectivamente, $9 \%$ e $91 \%$.

É importante ressaltar que essa empresa deixou de ser eficiente de um ano para outro e, embora tenha aumentado a relevância dos Investimentos sócio-ambientais no Faturamento da RGE, a mesma experimentou uma redução muito grande no input de Ativo Total.

A segunda empresa apresentada é a Celpe. No ano de 2003, o input Ativo Total foi contribuiu para 92\% do faturamento (output) da empresa. O input Investimentos sócio-ambientais contribuiu para $8 \%$ do Faturamento da empresa (output) e o input Mão-de-obra não contribuiu no Faturamento da mesma. No ano de 2004, o input Ativo Total respondeu por $80 \%$ do Faturamento da RGE, enquanto os inputs de Mão-de-obra e Investimento sócio-ambiental responderam por, respectivamente, $20 \%$ e $0 \%$.

Esta empresa também deixou de ser eficiente de 2003 para 2004. Na análise que foi realizada com as variáveis de input apresentadas, pode-se atribuir à falta de eficiência para esta empresa, fatores como: baixa contribuição dos Investimentos sócio-ambientais para o Faturamento 
da empresa, assim como à redução da contribuição dos Ativos Totais para o Faturamento da mesma.

E, por fim, a última empresa analisada é a Coelba, que passou a ser eficiente de 2003 para 2004. Em 2003, a margem de contribuição dos inputs Ativos Total, Mão-de-obra e Investimentos sócio-ambientais para o Faturamento (output) da empresa foi de, respectivamente, 74\%, 0\% e 25\%. Para o ano seguinte foi de, respectivamente, $0 \%, 3 \%$ e 97\%. O que isso quer dizer? Quer dizer que, entre outras coisas, no ano de 2004 a Coelba conseguiu transformar seu incremento em Investimentos sócio-ambientais em uma maior participação no Faturamento da empresa.

Como é possível perceber a partir desses exemplos empíricos, os investimentos sócio ambientais são fatores relevantes e possuem margem de contribuição significativa no desempenho financeiro das empresas. Observou-se individualmente a importância deste input para o alcance dos resultados encontrados. No entanto, outro fator que deve ser considerado é a questão da combinação de inputs para classificar a empresa como eficiente. Não basta possuir um nível relevante de Investimentos sócio-ambientais, deve ser considerado também o equilíbrio entre os demais inputs e a capacidade da empresas em revertê-los numa expansão do faturamento.

\section{Considerações finais}

O atual contexto econômico de abertura de mercados e acirrada competição é marcado pela busca de qualificações, por parte das empresas, a fim de assegurarem suas posições no mercado e buscarem novos espaços de atuação.

Esses fatores têm levado as empresas a buscarem diferenciais estratégicos, inclusive por meio da responsabilidade sócio-ambiental empresarial. Diversas são as ações tomadas rumo à esse objetivo, por exemplo, tratar com dignidade os seus funcionários, fabricar produtos adequados, prestar serviços de qualidade, veicular propaganda verdadeira, promover limpeza no ambiente de trabalho, não sujar ruas ou dificultar o trânsito, contribuir para as causas da comunidade, não explorar mão de obra infantil, escrava ou de qualquer forma incapaz de se defender, entre outras. Responsabilidade sócio-ambiental, hoje, pode ser a diferença entre vender e não vender.

O presente artigo propõe o início da discussão sobre o impacto dos investimentos em responsabilidade sócio-ambiental para o desempenho financeiro de empresas do setor de energia elétrica. Inicialmente, é possível observar a forte correlação entre esses investimentos e o faturamento das empresas, já que, por meio da aplicação da ferramenta DEA, foi possível concluir que o faturamento das empresas pode ter, como um dos fatores explicativos, os investimentos em responsabilidade sócio-ambiental. No entanto, embora seja relevante para o resultado financeiro das empresas, há de se reconhecer que este não é o único fator determinante de sucesso. 
Cabe ressaltar que, conforme observado, os investimentos em responsabilidade sócioambiental são relevantes sim, mas é necessário considerar outros fatores também, de forma a explicar o êxito de corporações. Há um mix de inputs que deve estar equilibrado para que a empresa obtenha bons resultados financeiros.

Uma importante restrição para as análises é referente à ausência de publicação de dados, relativos à investimentos sócio-ambientais, para anos anteriores aos investigados. Esse fator impossibilitou uma análise mais aprofundada sobre o impacto de tais investimentos para o resultado financeiro das empresas.

O debate sobre a relevância de ações socialmente responsáveis e sua relação com o desempenho financeiro das empresas é novo e deve ser incentivado, acompanhado por observações empíricas e análises quantitativas sobre o quanto a Responsabilidade Social Corporativa pode representar vantagem competitiva para a empresa e proporcionar benefícios à sociedade.

\begin{abstract}
This work sought to discuss the importance of social and environmental responsibility investments for corporate financial performance of electrical energy dealer companies. To reach it, the tool Data Envelopment Analysis (DEA) was used to calculate the efficiency of 12 companies of that sector, in the year of 2003 and 2004, and one of the main used inputs, for the calculation of the efficiency, was the social and environmental responsibility investments. The results obtained identify a strong correlation between corporate revenue and social and environmental responsibility investments.

Key-words: social and environmental responsibility investments; efficiency; data envelopment analysis.
\end{abstract}

\title{
Referências
}

BOWEN, Howard Rothman. Social responsibilities of the businessman. New York: Harper \& Row, 1953.

BRASIL. BANCO NACIONAL DO DESENVOLVIMENTO ECONÔMICO E SOCIAL. Empresas, responsabilidade corporativa e investimento social: uma abordagem introdutória. Relatório Setorial 1 . Rio de Janeiro: AS/GESET, mar. 2001.

CAJAZEIRA, J. E. R.; BARBIERI, J.C. A futura norma ISO 26.000 sobre responsabilidade social - barreira não tarifária ou comércio justo?. IN Encontro Nacional de Gestão Empresarial e Meio Ambiente, 8, Rio de Janeiro, Anais do ENGEMA, EBAPE/FGV, 2005.

CARROLL, Archie B. Corporate social responsibility. Business and Society. Chicago, v. 38, n. 3, p. 268-295, Sept. 1999.

CARROLL, Archie B. A three dimensional modelo for corporate perfomance. Academy of Management Review. Ada, vol. 4, n. 4, p. 497-505, 1979.

CASA NOVA, S. P. C. Utilização da Análise por Envoltória de Dados (DEA) na análise de demonstrações contábeis. Tese (Doutorado). Universidade de São Paulo, São Paulo, 2002. 
DAVIS, Keith. Can business afford to ignore social responsibilities? Califórnia Management Review. Berkeley, v. 2, n. 3, p. 70-76, Spring 1960.

DRUCKER, Peter F. The new meaning of corporate social responsibility. Califórnia Management Review. Barkeley, v. 26, n. 2, p. 53-63, Winter 1984.

FARREL, M. J. The measurement of productive efficiency. Journal of the Royal Statistic Society. P. 253-290, 1957.

FISCHER, Rosa Maria. A responsabilidade pelo desenvolvimento. São Paulo, 2003. Texto de Apoio à Prova de Erudição do Concurso para Provimento do Cargo de Professor Titular do Departamento de Administração da Faculdade de Economia, Administração e Contabilidade da Universidade de São Paulo.

GRIFFIN, Jennifer J.; MAHON, John F. The corporate social performance and corporate financial performance debate: twenty-five years of incomparable research. Business and Society. Chicago, v. 36, n. 1, p. 5-31, Mar. 1997.

JONES, Thomas M. Corporate social performance revisited, redefined. Califórnia Management Review. Berkeley, v. 22, n. 3, p. 59-67, Spring 1980.

KRAEMER, M. E. P. Responsabilidade Social - Uma alavanca para a sustentabilidade. Itajaí, Santa Catarina. p.1$15,2004$.

MCGUIRE, Joseph W. Business and society. New York: McGraw-Hill, 1963.

OLIVEIRA, H. C; GOMES, A. P. Eficiência na agroindústria avícola mineira. In: CONGRESSO DE CIÊNCIAS HUMANAS, LETRAS E ARTES. Ouro Preto, 28 - 31 ago, 2001.

PAVA, Moses L.; KRAUSZ, Joshua. The association between corporate social responsability and financial performance: the paradox osf social cost. Journal of Business Ethics. Dordrecht, v. 15, n. 3, p. 321-357, Mar. 1996.

cross ${ }^{\text {ref }}$

STANWICK, Peter A.; STANWICK, Sarah, D. The relationship between corporate social performance, and organizational size, and environmental performance: an empirical examination. Journal of Business Ethics. Dordrecht, v. 17 , n. 2, p. 195-204, 1998.

cross ${ }^{\text {ref }}$

ULLMANN, Arieh. Data in search of a theory: a critical examination of the relationship among social performance, social disclosure, and economic performance. Academy of Management Review. Ada, v. 10, n. 2 , p. $540-577,1985$

\section{Dados dos autores:}

Naja Brandão Santana

Universidade de São Paulo - Escola de Engenharia de São Carlos

Estudante de pós-graduação: Mestrado

Rua Iwagiro Toyama, n 101, apt. 04. São Carlos, São Paulo, Brasil. CEP: 13564-380

Telefones: (16) 3361.1914; (16) 9208.0369

e-mail:naja@prod.eesc.usp.br 
Ana Elisa Périco

Universidade de São Paulo - Escola de Engenharia de São Carlos

Estudante de pós-graduação: Doutorado

Rua Iwagiro Toyama, $n^{\circ}$ 101, apt. 04. São Carlos, São Paulo, Brasil. CEP: 13564-380

Telefones: (16) 3361.1914; (16) 9198.8899

e-mail: anaelisa@prod.eesc.usp.br

Daisy Aparecida do Nascimento Rebelatto

Universidade de São Paulo - Escola de Engenharia de São Carlos

Professora Associada

Avenida Trabalhador Sãocarlense, $n^{\circ} 400$, Centro

São Carlos - São Paulo - Brasil - CEP: 13566-590

Telefone: (16) 3373.9381

e-mail:daisy@prod.eesc.usp.br

Recebido para publicação em: 28/10/2006

Aceito para publicação em: 27/11/2006 